\title{
The ARM Mobile Facility and its first international deployment: measuring radiative flux divergence in West Africa
}

Article

Published Version

Miller, M. A. and Slingo, A. (2007) The ARM Mobile Facility and its first international deployment: measuring radiative flux divergence in West Africa. Bulletin of the American Meteorological Society, 88 (8). pp. 1229-1244. ISSN 15200477 doi: https://doi.org/10.1175/BAMS-88-8-1229 Available at https://centaur.reading.ac.uk/867/

It is advisable to refer to the publisher's version if you intend to cite from the work. See Guidance on citing.

Published version at: http://dx.doi.org/10.1175/BAMS-88-8-1229

To link to this article DOI: http://dx.doi.org/10.1175/BAMS-88-8-1229

Publisher: American Meteorological Society

All outputs in CentAUR are protected by Intellectual Property Rights law, including copyright law. Copyright and IPR is retained by the creators or other copyright holders. Terms and conditions for use of this material are defined in the End User Agreement.

www.reading.ac.uk/centaur 
Central Archive at the University of Reading

Reading's research outputs online 


\title{
THE ARM MOBILE FACILITY AND ITS FIRST INTERNATIONAL DEPLOYMENT Measuring Radiative Flux Divergence in West Africa
}

\author{
by Mark. A. Miller and Anthony Slingo
}

The ARM Mobile Facility is a transportable community climate research platform containing sophisticated sensors that are used to study radiation transfer and other atmospheric processes.
AFFILIATIONS: MILLER-Brookhaven National Laboratory, Upton, New York; SLINGO-Environmental Systems Science Centre, University of Reading, Reading, United Kingdom CORRESPONDING AUTHOR: Mark A. Miller, Brookhaven National Laboratory, ASD/BIdg. 490D, Upton, NY 11973 E-mail:miller@bnl.gov

The abstract for this article can be found in this issue, following the table of contents.

DOI:I0.II75/BAMS-88-8-1229

In final form 25 January 2007

(C) 2007 American Meteorological Society regions of interest to the general atmospheric science community. The AMF is designed to operate continuously for periods of 6-12 months and includes a core suite of active remote sensors that are similar to those at the fixed sites. Deployments are determined through an international proposal competition and data are freely distributed through the ARM archive (www.arm.gov), typically in near-real time.

The purpose of this paper is to describe the AMF instrumentation and its charter as a Department of Energy Facility, and to demonstrate the use of the AMF in its first international field deployment in Niamey, Niger. This deployment is associated with two large international campaigns: the African Monsoon Multidisciplinary Analysis (AMMA; Lebel et al. 2003) and the Geostationary Earth Radiation Budget (GERB; Harries et al. 2005; Allan et al. 2005) experiment. The proposal to the ARM program leading to this deployment was titled "Radiative Atmospheric Divergence Using the AMF, GERB Data, and AMMA Stations (RADAGAST)." It represents an international effort to measure continuously the radiative fluxes at the surface and top of the atmosphere through the seasonal progression of the West African Monsoon, which is strongly impacted by Saharan dust, biomass burning, and the devel- 
opment of deep convection in association with the intertropical convergence zone.

INSTRUMENTATION. The AMF is designed to continuously sample cloud, aerosol, thermodynamics, and wind conditions in a relatively narrow column above the deployment location, and to measure the fluxes of radiation, latent heat, sensible heat, and carbon dioxide at the surface. The centerpieces of the AMF are a collection of active and passive remote sensors (Table 1) including a vertically pointing 95-GHz Doppler radar (3.2-mm wavelength), which provides a profile of effective reflectivity factor and a full spectrum of the Doppler velocities at each range gate (Lhermitte 1987; Clothiaux et al. 1995; Kollias et al. 2006; Fig. 1; the sidebar). The operating frequency of this radar was selected to minimize unwanted echoes from insects typically observed at longer wavelengths and to enable advanced signal-processing techniques that rely on unique radar backscatter characteristics when hydrometeors reach the proportions of drizzle $(100 \mu \mathrm{m})$. Because of its 3.2-mm wavelength, the AMF 95-GHz Doppler radar is capable of detecting small cloud droplets with diameters of $5-10 \mu \mathrm{m}$. It is sensitive enough to detect most clouds in the column with the exception of cloud layers that contain particles of unusually small size, number concentration, or both, or are sufficiently thin, in a geometric sense, so that they fill only a limited amount of the sampling volume. Cloud detection deficiencies are more probable in the upper troposphere because less of the transmitted power is incident on the hydrometeors. The radar has a relatively narrow beamwitdth $\left(<1^{\circ}\right)$, resulting in a small sampling volume, and deployments of similar cloud radars over the past decade have produced optimized sampling configurations (Kollias et al. 2005). The radar reflectivity and Doppler velocity spectrum in lightly precipitating clouds can be measured with a vertical resolution on the order of $30 \mathrm{~m}$ and a temporal resolution on the order of $2 \mathrm{~s}$. Some clouds contain both cloud droplet size and drizzle size particles, which are larger than $\sim 20 \mu \mathrm{m}$ (e.g., a bimodal droplet distribution). Advanced signal-processing techniques may provide information about the droplet size distribution of the drizzle in this circumstance. Determination of cloud microphysical properties in mixed-phase and ice clouds is less certain, though recent developments suggest that discrimination of particle phase using the Doppler spectrum is possible under some circumstances (Kollias et al. 2006).

The location of the cloud base is fundamental to radiation transfer and cloud formation in the atmosphere. Cloud base is defined as the lowest level in the atmosphere at which the air contains a percep-

\begin{tabular}{|c|c|c|c|}
\hline Instrument & Measurement & Resolution & Comments \\
\hline $\begin{array}{l}95-\mathrm{GHz} \text { cloud } \\
\text { radar (WACR) }\end{array}$ & $\begin{array}{l}\text { Effective reflectivity factor and } \\
\text { Doppler spectrum }\end{array}$ & $\begin{array}{l}\text { Range: } 30 \mathrm{~m} \\
\text { Time: } 2 \mathrm{~s}\end{array}$ & $\begin{array}{l}\text { Minimum detectable signal: } \\
-50 \mathrm{dBZ} \text { at } 2 \mathrm{~km}\end{array}$ \\
\hline MPL & Backscatter intensity: $523.5 \mathrm{~nm}$ & $\begin{array}{l}\text { Range: } 30 \mathrm{~m} \\
\text { Time: } 30-60 \mathrm{~s}\end{array}$ & Maximum height: 18 km \\
\hline MWR & $\begin{array}{l}\text { Brightness temperature ( } 5 \text { channels), } \\
\text { cloud liquid water path, precipitable } \\
\text { water vapor }\end{array}$ & $\begin{array}{l}\text { Time: } 20 \mathrm{~s} \\
\text { Integrated quantities }\end{array}$ & $\begin{array}{l}\text { Minimum detectable cloud } \\
\text { liquid water path: } 20-30 \mathrm{~g} \mathrm{~m}^{-2}\end{array}$ \\
\hline MWR-P & $\begin{array}{l}\text { Brightness temperature ( } 12 \text { channels), } \\
\text { cloud liquid water path, temperature } \\
\text { and water vapor profiles }\end{array}$ & $\begin{array}{l}\text { Time: } 5 \text { min } \\
\text { Range: variable }\end{array}$ & $\begin{array}{l}\text { Range resolution dependent on } \\
\text { atmospheric conditions }\end{array}$ \\
\hline AERI & $\begin{array}{l}\text { Absolute infrared spectral radiance } \\
\text { in } 1.3^{\circ} \text { field of view; temperature and } \\
\text { vapor profiles }\end{array}$ & $\begin{array}{l}\text { Spectral: } 3-19.2 \mu \mathrm{m} \text { with } \\
3.3-36-\mathrm{nm} \text { resolution } \\
\text { Time: } 6 \mathrm{~min} \\
\text { Range: variable }\end{array}$ & $\begin{array}{l}\text { Temporal resolution will be } \\
\text { improved to } 20 \mathrm{~s} \text { in near future }\end{array}$ \\
\hline Laser ceilometer & $\begin{array}{l}\text { Cloud-base height, backscatter } \\
\text { intensity }\end{array}$ & $\begin{array}{l}\text { Range: } 15 \mathrm{~m} \\
\text { Time: } 30 \mathrm{~s}\end{array}$ & Maximum height is $\sim 5.5 \mathrm{~km}$ \\
\hline $\begin{array}{l}\text { I040-MHz wind } \\
\text { profiler }\end{array}$ & $\begin{array}{l}\text { Wind profile, precipitation Doppler } \\
\text { velocity spectrum }\end{array}$ & $\begin{array}{l}\text { Time: } 6 \mathrm{~min} \\
\text { Resolution: } 75 \mathrm{~m}\end{array}$ & 3 beams \\
\hline Rawindsondes & $\begin{array}{l}\text { Pressure, temperature, relative } \\
\text { humidity, winds }\end{array}$ & Time: Minimum of every $6 \mathrm{~h}$ & $\begin{array}{l}\text { Moisture profile humidity } \\
\text { profile scaled by MWR }\end{array}$ \\
\hline
\end{tabular}




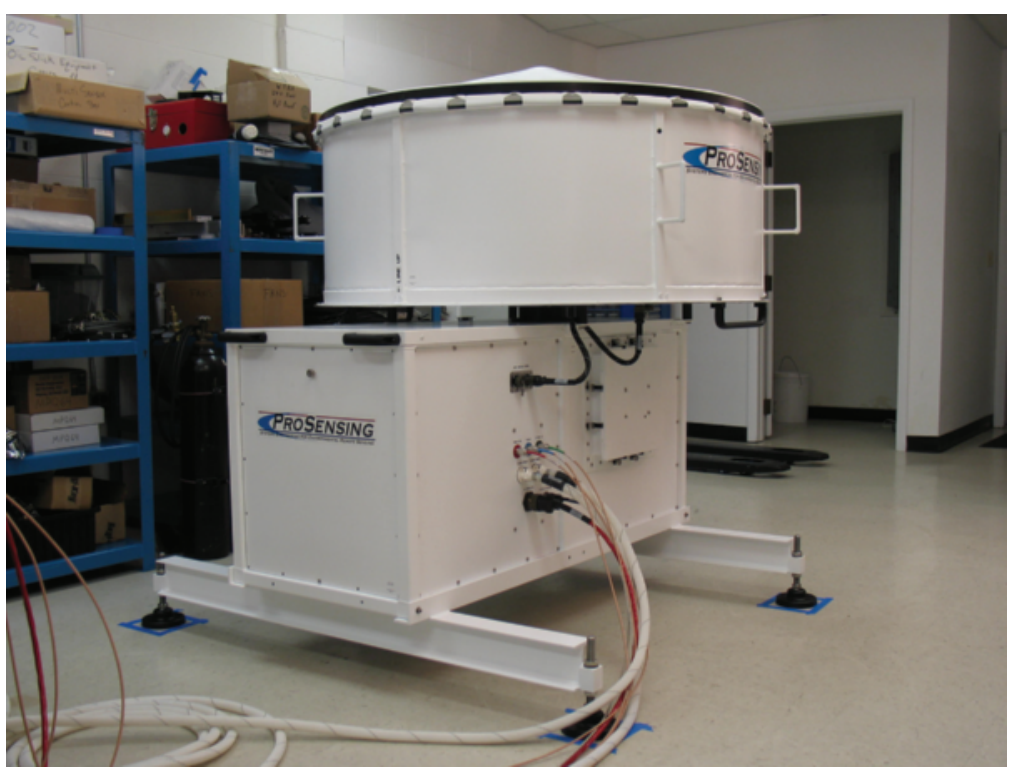

FIG. I. The AMF 95-GHz Doppler radar.

tible quantity of cloud particles (Huschke 1959). An observer using only a visual inspection of an isolated thick cloud in a broken cloud field will identify the "optical" cloud base as the location where there is noticeable bluish tint and a reduction in intensity of scattered diffuse radiation. The observer may not visually detect a few scattered drizzle or raindrops below the perceptible optical cloud base because they do not scatter enough visible radiation compared to the smaller cloud droplets. These falling particles represent a double-edged sword because they typically have minimal direct impact on the diffuse or direct radiation at that moment but may have an important impact on the overall radiative budget of the cloud system through their ability to reduce cloud liquid water. Detection of the optical cloud-base height is difficult using a $95-\mathrm{GHz}$ radar because of extreme sensitivity to drizzle size and larger droplets that are often found in the vicinity of the optical base. Therefore, lidar is used to identify the optical cloud base, and the $95-\mathrm{GHz}$ radar to quantify the cloud water flux above, through, and below the optical cloud base.

A micropulse lidar (MPL) that transmits at a wavelength of $523 \mathrm{~nm}$ with a vertical resolution of $30 \mathrm{~m}$ is the primary cloud-base detector for the AMF (Spinhirne 1993; Campbell et al. 2002). A ceilometer operating in the near-infrared wavelength band $(905 \mathrm{~nm})$ with a vertical resolution of $15 \mathrm{~m}$ serves as a backup to increase overall system reliability. The MPL can measure lowest cloud-base heights even when they are high in the troposphere $(18 \mathrm{~km})$, while the ceilometer measures cloud base to approximately $5 \mathrm{~km}$. Lidar backscatter profiles are recorded for both systems and the profile from the MPL can be used in clear skies to map vertical aerosol structure.

The column-integrated water vapor and liquid water are measured by recording passive emissions from the atmosphere in the microwave region using a Microwave Radiometer (MWR; Liljegren et al. 2001; Westwater et al. 2001). All of the water molecules in the column emit in the microwave region of the electromagnetic spectrum, although different phases of water have emission peaks in slightly different regions of the spectrum. ${ }^{1}$ Research suggests that this technique is accurate when
${ }^{1}$ The emission spectra of water vapor and liquid water have considerable overlap, but water vapor is more dominant in the vicinity of $22 \mathrm{GHz}$ (location of a water vapor absorption band) and liquid water in the vicinity of $31 \mathrm{GHz}$ (location of a minimum in water vapor absorption). Simultaneous measurements of the emissions in these two channels produce two equations and two unknowns that can be solved to produce estimates of the column-integrated water vapor and liquid water.

\section{USE OF THE FULL SPECTRUM OF DOPPLER VELOCITIES FOR CLOUD MICROPHYSICS RESEARCH}

The AMF cloud radar continuously points toward zenith and measures the distribution of vertical velocities of hydrometeors (or the Doppler vertical velocity spectra) at each measurement height within the radar beam. The fall velocity of hydrometeors is a known function of droplet size, which provides an opportunity to map the measured fall velocities to specific hydrometeor sizes. Cloud droplets have a small upward vertical velocity, while precipitation has a larger downward vertical velocity. There is, of course, a continuum of droplet sizes in most clouds, so the distinction between cloud particles and falling precipitation is not always well defined. But incloud turbulence also contributes to the vertical velocity spectrum. Turbulence in the cloud broadens the droplets velocity distribution, often making it difficult to associate a given fall velocity with a given size of hydrometeor (Kollias and Albrecht 2000; Kollias et al. 200I). This problem is particularly acute for cloud droplets, although there are occasionally quiescent periods when turbulence is minimal and some information about the cloud droplet spectrum may be obtained. 
the liquid water path exceeds $20-30 \mathrm{gm}^{-2}$ (Turner et al. 2007), though new algorithms may reduce this uncertainty in coming years.

The AMF has a 12-channel MWR profiler (MWR-P) whose vertical resolution varies according to the atmospheric conditions. Extra microwave frequencies are added to sample the detailed structure of the water vapor and oxygen emission (absorption) peaks, which ultimately contains information about the thermodynamic profile (Gary 1988; Güldner and Spanküch 2001). At the center of an absorption line, the microwave emission is strongly weighted toward the lowest levels of the atmosphere, while incremental excursions on either side of the absorption line are weighted toward increasingly higher levels in the atmosphere. Adding four frequencies around $22 \mathrm{GHz}$ enables low-resolution vertical profiles of the water vapor to be obtained through mathematical inversion of a set of equations and the use of a radiation transfer model. Sampling the structure of the oxygen absorption line with additional frequencies in the region between 50 and $60 \mathrm{GHz}$ provides a low-resolution temperature profile because the temperature of the atmosphere determines the oxygen emission.

An Atmospheric Emitted Radiance Interferometer (AERI) measures the infrared emission spectrum in great detail (Feltz et al. 1998). Applications of the AERI include derivation of thermodynamic profiles, cloud microphysical properties, and specific information about the composition of atmospheric constituents, such as dust (Smith et al. 1999; Collard et al. 1995; Turner et al. 2004). Thermodynamic profiling in clear skies is accomplished in a manner similar to the MWR, where the detailed shape of an emission line is used to provide information about the vertical structure of the atmosphere. In cloudy skies, the AERI can be used to compute the liquid water path when clouds are too thin to overcome the noise level and uncertainty of microwave radiometer measurements. Specific regions within the infrared spectrum are also associated with characteristics of the cloud droplet spectrum (Turner 2005; Lubin and Vogelmann 2006).

A three-beam Doppler UHF profiler (915- or $1036-\mathrm{MHz}$ frequency, depending on deployment location) is used to measure the wind structure to a range of $5 \mathrm{~km}$ with $75-\mathrm{m}$ vertical resolution (Ecklund et al. 1988). The scattering targets for this radar are mainly clusters of water molecules that are spaced geometrically in a manner that enables the microwave radiation transmitted from the radar to experience constructive interference when it is scattered (Bragg scatter), thereby boosting the received power level at the radar antenna. These clusters are associated with turbulent eddies imbedded in the larger-scale flow and are thus tracers of the wind. Their Doppler velocity is measured along three beams, as required to measure the horizontal and vertical wind flow: a zenith beam and two off-zenith beams $\left(15^{\circ}\right)$ that are perpendicular to one another. This UHF radar can also measure the fall velocity of raindrops during precipitation (Gossard et al. 1982; Gossard 1988).

The AMF remote sensors described above provide information about the thermodynamic and wind profiles, though each has caveats that restrict performance in certain conditions and in certain parts of the troposphere. These remotely sensed data are augmented by the proverbial "gold standard," which is rawindsonde launches at a rate of at least four per day. The rawindsondes used for these launches are Vaisala model RS-92.

Broadband downwelling irradiance is measured at the surface using standard pyranometers. A solar tracker is used to shade the solar disk on one pyranometer, thereby yielding the diffuse irradiance, and a normal incidence pyroheliometer mounted on the tracker simultaneously measures the direct component of the irradiance. A complementary set of unshaded pygeometers measures the total broadband irradiance. Spectral components of the shortwave direct, diffuse, and total irradiances are measured using a multiple-frequency rotating shadow band radiometer (MFRSR), which dissects the irradiance into seven narrow bands, each of 10-nm width (Harrison and Michalsky 1994a,b). These bands can be used to retrieve information about aerosol optical thickness and particle size, and the ozone and water vapor absorption. Coincident broadband longwave measurements are made by shaded and unshaded pyrgeometers (no measurement of the normal incidence is attempted).

Upwelling shortwave and longwave irradiances are measured using pyranometers and pyrgeometers that are identical to those used to make the downwelling measurements, although no shading is required (Table 2). The upwelling radiometers are mounted approximately $2 \mathrm{~m}$ above the surface and are particularly susceptible to local influences because surface conditions may vary widely over the region where the AMF is deployed. An ancillary surface radiation package described later is occasionally deployed to ameliorate this problem and to provide additional information that can be used to evaluate local influences that may be present in the AMF surface radiation data.

Two additional sensors provide information about the state of the sky and the infrared temperature of the atmospheric column above the AMF location. A 


\begin{tabular}{|c|c|c|c|}
\hline Instrument & Measurement & Resolution & Comments \\
\hline $\begin{array}{l}\text { Downwelling radiation } \\
\text { (SKYRAD) }\end{array}$ & $\begin{array}{l}\text { Direct, diffuse, and global } \\
\text { broadband shortwave (solar), } \\
\text { longwave (infrared) }\end{array}$ & Time: I min & Included in ancillary facility \\
\hline $\begin{array}{l}\text { Upwelling radiation } \\
\text { (GNDRAD) }\end{array}$ & $\begin{array}{l}\text { Broadband shortwave (solar) and } \\
\text { longwave (infrared) }\end{array}$ & Time: I min typically $2 \mathrm{~m}$ & Included in ancillary facility \\
\hline $\begin{array}{l}\text { Multifilter Rotating } \\
\text { Shadowband Radiometer }\end{array}$ & $\begin{array}{l}\text { Aerosol optical thickness, aerosol } \\
\text { Angstrom exponent, cloud optical } \\
\text { thickness }\end{array}$ & Time: $20 \mathrm{~s}$ & $\begin{array}{l}\text { Channels: } 415,500,615,673 \text {, } \\
870,940 \mathrm{~mm} \text { with } 10-\mathrm{nm} \\
\text { width, and a broadband channel }\end{array}$ \\
\hline $\begin{array}{l}\text { Infrared thermometer } \\
\text { (IRT) }\end{array}$ & Cloud-base temperature & Time: $<$ I min & $\begin{array}{l}\text { Cloud must be a blackbody } \\
\text { (emissivity = I) }\end{array}$ \\
\hline Total sky imager & $\begin{array}{l}\text { Visible hemispheric sky images } \\
\text { for daylight hours (e.g., similar to } \\
\text { pictures from an all sky camera) }\end{array}$ & Time: $\sim 30 \mathrm{~s}$ & Solar elevation $>5^{\circ}-10^{\circ}$ \\
\hline Eddy correlation & $\begin{array}{l}\text { Surface turbulent fluxes of } \\
\text { momentum, sensible heat, latent } \\
\text { heat, carbon flux }\end{array}$ & Time: one-half hour & $\begin{array}{l}\text { Mounted at height determined } \\
\text { by surface characteristics }\end{array}$ \\
\hline Surface meteorology & $\begin{array}{l}\text { Surface wind speed and direction, } \\
\text { temperature, relative humidity, } \\
\text { barometric pressure, rain rate, } \\
\text { and visibility }\end{array}$ & Time: I min & Mounted on $10-\mathrm{m}$ tower \\
\hline
\end{tabular}

Total Sky Imager (TSI) captures a digital image of the sky condition every $30 \mathrm{~s}$ during the daylight hours (Long and DeLuisi 1998). This image is analyzed to determine the cloud coverage and to provide a qualitative description of the clouds that are present in the column (percent of opaque and thin clouds). A narrow-beam infrared thermometer (IRT) measures the temperature at cloud base when the clouds are thick enough to radiate as a blackbody (optically thick) and can be combined with lidar measurements to estimate cirrus cloud properties.

Surface latent and sensible heat fluxes and the carbon flux are measured by an eddy correlation system (Webb et al. 1980; Moore 1986). The area of the land surface represented by these flux measurements (footprint) is determined by the atmospheric state, surface conditions, and measurement height above the surface (Leclerc et al. 1997; Schuepp et al. 1992), so the eddy correlation system is mounted at a height that is consistent with the scientific objectives of the deployment. Standard meteorological variables, including rainfall rate (liquid water flux) and surface visibility, are also measured at the surface.

The AMF has an Aerosol Observing System (AOS) that measures the optical and cloud-forming properties of aerosol particles. Seasonal measurements of these properties are useful for characterizing specific aerosol types as well as obtaining aerosol climatology for the region. The visible light scattering and absorption coefficients of the aerosols are measured at three wavelengths and in two particle size ranges: sub-10- and sub-1- $\mu \mathrm{m}$ diameter (Fig. 2; Table 3). Two size ranges are required because aerosol optical properties, sources, sinks, and chemical composition are strongly dependent on particle size. Changes in these optical properties over a range from $\sim 40 \%$ to $90 \%$ relative humidity are measured with a humidified nephelometer. It is possible to derive the aerosol single scattering albedo, asymmetry parameter, and hygroscopic growth factor from these measurements, which are parameters that can be used to constrain calculations of aerosol radiative forcing ${ }^{2}$ on long time scales (Fiebig and Ogren 2006; Andrews et al. 2006; Anderson and Ogren 1998; Anderson et al. 1999; Bond et al. 2001). Measurements of the number concentration of cloud condensation nuclei (CCN) as a function of the supersaturation are used to determine the cloud-forming properties of the aerosol.

The AMF AOS system inlet adapts easily to the local climate conditions and the research priorities of the deployment (Fig. 2b). It may be desirable to sample interstitial particles separately from cloud droplets in cloudy or foggy conditions (as was the case at Pt. Reyes, California), so a counterflow virtual impactor (CVI) may be used on the sample inlet. The

${ }^{2}$ Radiative forcing is defined as the radiative heating of cooling effect of aerosol on the atmosphere 

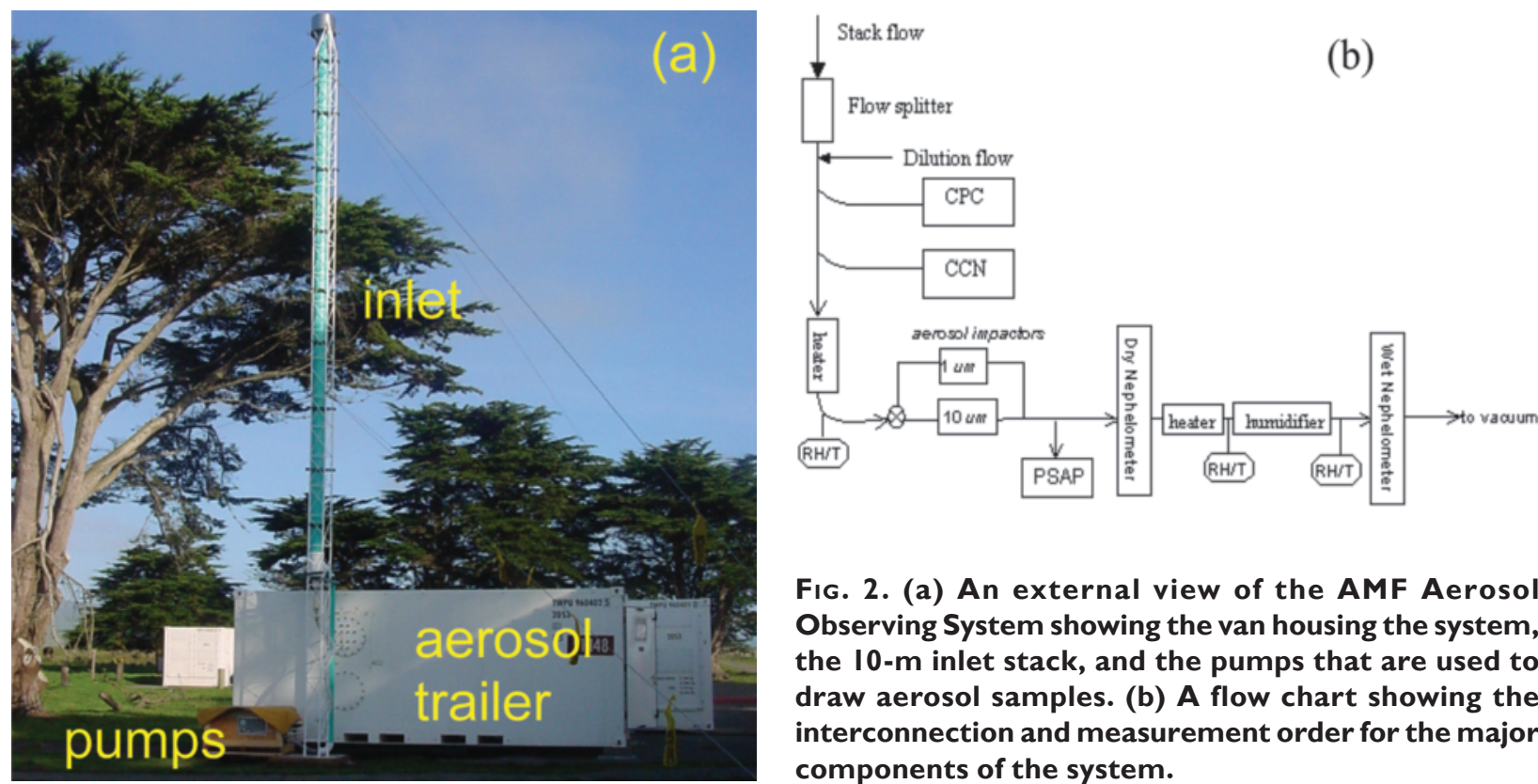

FIg. 2. (a) An external view of the AMF Aerosol Observing System showing the van housing the system, the $10-\mathrm{m}$ inlet stack, and the pumps that are used to draw aerosol samples. (b) A flow chart showing the interconnection and measurement order for the major components of the system.

TABle 3. The AMF Aerosol Observing System.

\begin{tabular}{|c|c|c|}
\hline Instrument & Description of measurement & Comments \\
\hline $\begin{array}{l}\text { Integrating "dry" nephelometer } \\
\text { (operated at low RH) }\end{array}$ & $\begin{array}{l}\text { Total scattering between } 7^{\circ} \text { and } 170^{\circ} \text { and } \\
\text { backscattering between } 90^{\circ} \text { and } 170^{\circ} \text { at a } \\
\text { relative humidity of } 50 \%\end{array}$ & $\begin{array}{l}\text { Three measurement wavelengths: } \\
\text { blue }(450 \mathrm{~nm}) \text {, green }(550 \mathrm{~nm}) \text {, and } \\
\text { red }(700 \mathrm{~nm})\end{array}$ \\
\hline $\begin{array}{l}\text { Integrating "wet" nephelometer (RH } \\
\text { scanned from } \sim 40 \%-90 \% \text { over a } 6 \text {-min } \\
\text { interval, twice per hour) }\end{array}$ & $\begin{array}{l}\text { Total scattering between } 7^{\circ} \text { and } 170^{\circ} \\
\text { and backscattering between } 90^{\circ} \text { and } \\
170^{\circ} \text { at relative humidities scanned from } \\
\sim 40 \%-90 \%)\end{array}$ & $\begin{array}{l}\text { Three measurement wavelengths: } \\
\text { blue }(450 \mathrm{~nm}) \text {, green }(550 \mathrm{~nm}) \text {, and } \\
\text { red }(700 \mathrm{~nm})\end{array}$ \\
\hline $\begin{array}{l}\text { Particle/soot absorption photometer } \\
\text { (operated at low RH) }\end{array}$ & $\begin{array}{l}\text { Filter-based method that measures light } \\
\text { absorption by dry aerosol particles }\end{array}$ & $\begin{array}{l}\text { Three measurement wavelengths: } \\
\text { blue }(467 \mathrm{~nm}) \text {, green }(530 \mathrm{~nm}) \text {, and } \\
\text { red }(660 \mathrm{~nm})\end{array}$ \\
\hline Condensation nuclei counter & $\begin{array}{l}\text { Total number of concentration of } \\
\text { condensation particles }\end{array}$ & Size range of $10 \mathrm{~nm}$ to $3 \mu \mathrm{m}$ \\
\hline $\begin{array}{l}\text { Multiple-supersaturation } \mathrm{CCN} \\
\text { activation counter }\end{array}$ & $\begin{array}{l}\text { Total number of } \mathrm{CCN} \text { as a function of } \\
\text { supersaturation }\end{array}$ & $\begin{array}{l}\text { Up to seven adjustable } \\
\text { supersaturations (currently } 0.079 \text { to } \\
\text { I.366) }\end{array}$ \\
\hline
\end{tabular}

CVI sorts particles into two sample streams: those with a diameter greater than $5 \mu \mathrm{m}$ and those with a diameter less than $5 \mu \mathrm{m}$. Because fog is not a prominent element of the climatology of Niamey, the CVI was omitted from the system, but a diluter was placed on the sample inlet to dilute the sample flow with dry, particle-free air. This sampling arrangement served the dual purpose of minimizing instrument clogging by large dust particles and reducing the sample air relative humidity during the wet season. In the sample stream of particles with a diameter less than $5 \mu \mathrm{m}$, the total concentration of all aerosol particles with a diameter larger than $10 \mathrm{~nm}$ is measured with a condensation particle counter (CPC).
A nephelometer measures the angular dependence of the scattering properties of aerosol particles, while a particle soot absorption photometer (PSAP) measures the amount of visible radiation absorbed at set wavelengths. The relative humidity of the aerosol sample is initially maintained, by heating, at a value just less than $40 \%$, which effectively dries the particles without causing the evaporation of volatile species like nitric or organic acids. This is necessary to measure the aerosol properties independent of relative humidity. "Dry" nephelometer measurements that are made at this reduced relative humidity enable the calculation of dry extinction. The dry absorption, total scattering, and backscattering coefficients 
are measured coincidentally at $\sim 450$ (blue; $467-\mathrm{nm}$ PSAP), 550 (green; 530-nm PSAP), and $700 \mathrm{~nm}$ (red; 660-nm PSAP). Adjusting the measurements to common blue, green, and red wavelengths enables estimates of the extinction coefficients at these wavelengths, which is the sum of the absorption and scattering coefficients. To quantify the relative humidity dependence of these dry aerosol scattering properties, the relative humidity is incrementally increased twice per hour through a range from $40 \%$ to $90 \%$, and scattering measurements are made at incremental humidities with a second "wet" nephelometer.

The cloud-forming properties of sampled aerosols are revealed by the CCN activation curve, ${ }^{3}$ which is measured over a 30 -min period at seven discrete supersaturations using a CCN activation counter (Roberts and Nenes 2005; 0.079 to 1.366 are currently used). This activation curve is related to the in-cloud updraft velocity because higher updraft velocities may produce larger supersaturations, depending on the nature of the CCN. Therefore, the CCN activation curve is a link between in-cloud dynamic processes, aerosols, and the cloud droplet size distribution. The ratio of the CCN number density to the total particle concentration measured with the CPC gives the fraction of aerosol that activates at a given supersaturation.

All data collected using the AMF core instruments are made available to the public in near-real time. Data are transferred to a data management facility where instrument status is monitored, initial quality control is performed, and files are converted to a standard format network Common Data Form (netCDF). Certain data streams are subjected to higher-level processing to produce additional geophysical variables prior to release, and efforts are made to release data for general use as soon as possible.

SITE SELECTION PROCESS. The AMF is deployed for periods ranging from six months to one year through an international proposal competition that is judged by the ARM Climate Research Facility Board. This board is comprised of four members from the ARM Science Team, excluding the AMF Site Scientist, and five members from other agencies, programs, and disciplines. This ensures that the AMF serves as a community facility and the deployment locations support a broad range of scientific objectives. Proposals are solicited once per year and ranked by potential scientific impact, cost, operational feasibility, and potential leverage in the form of con-

${ }^{3}$ The number of condensation nuclei that act as CCN as a function of the supersaturation. tributions to the proposed project by other entities. (More information about the proposal process can be obtained online at www.arm.gov/science/fc.stm.)

\section{THE RADAGAST PROJECT: THE FIRST INTERNATIONAL DEPLOYMENT OF} THE AMF. The AMF was initially deployed for six months at Pt. Reyes National Seashore in support of the Marine Stratus Radiation, Aerosol, and Drizzle Experiment (MASRAD; www.arm.gov/pubications/ programdocs/doe-er-arm-050I.pdf). Subsequently, a proposal entitled the Radiative Atmospheric Divergence Using ARM Mobile Facility, GERB Data and AMMA Stations (RADAGAST) was submitted to ARM by the second author and was selected for implementation. Under this project, the AMF was deployed at Niamey (Fig. 3) for the whole of 2006. The scientific motivation and observations that contribute to this project are described below.

Scientific background to the RADAGAST experiment. Despite good progress over the last few decades in quantifying the physical processes that control the interaction of solar and thermal radiation with the atmosphere and surface, a number of important gaps in our understanding remain. These gaps are highlighted by disagreements between observations and numerical radiative transfer schemes. Clouds present some of the most difficult problems, which include the radiative properties of ice and mixed-phase clouds, as well as the quantification of 3D effects (Cahalan et al. 2005). It is also recognized that aerosols make a substantial contribution to current uncertainties, not only through their direct effects on the radiation fields, but also through their indirect effects on cloud microphysics and radiative properties. Both effects are extremely uncertain because of the wide range of aerosol types and properties, and the complexity of the interactions between aerosols, water drops, and ice crystals (Haywood and Boucher 2000). An added difficulty is that the vertical distribution of aerosol is often not represented by detailed measurements of aerosol chemistry and scattering properties made at the surface. Even in clear skies, where progress has been particularly impressive for longwave radiation (Turner et al. 2004), there are discrepancies that are compounded by the complex spectrum of water vapor absorption, which includes thousands of weak spectral lines and a strong underlying continuum, neither of which have yet been fully quantified (Pilewskie et al. 2000; Ptashnik et al. 2004).

In addition to the specific process problems mentioned above, there are more general difficulties in 


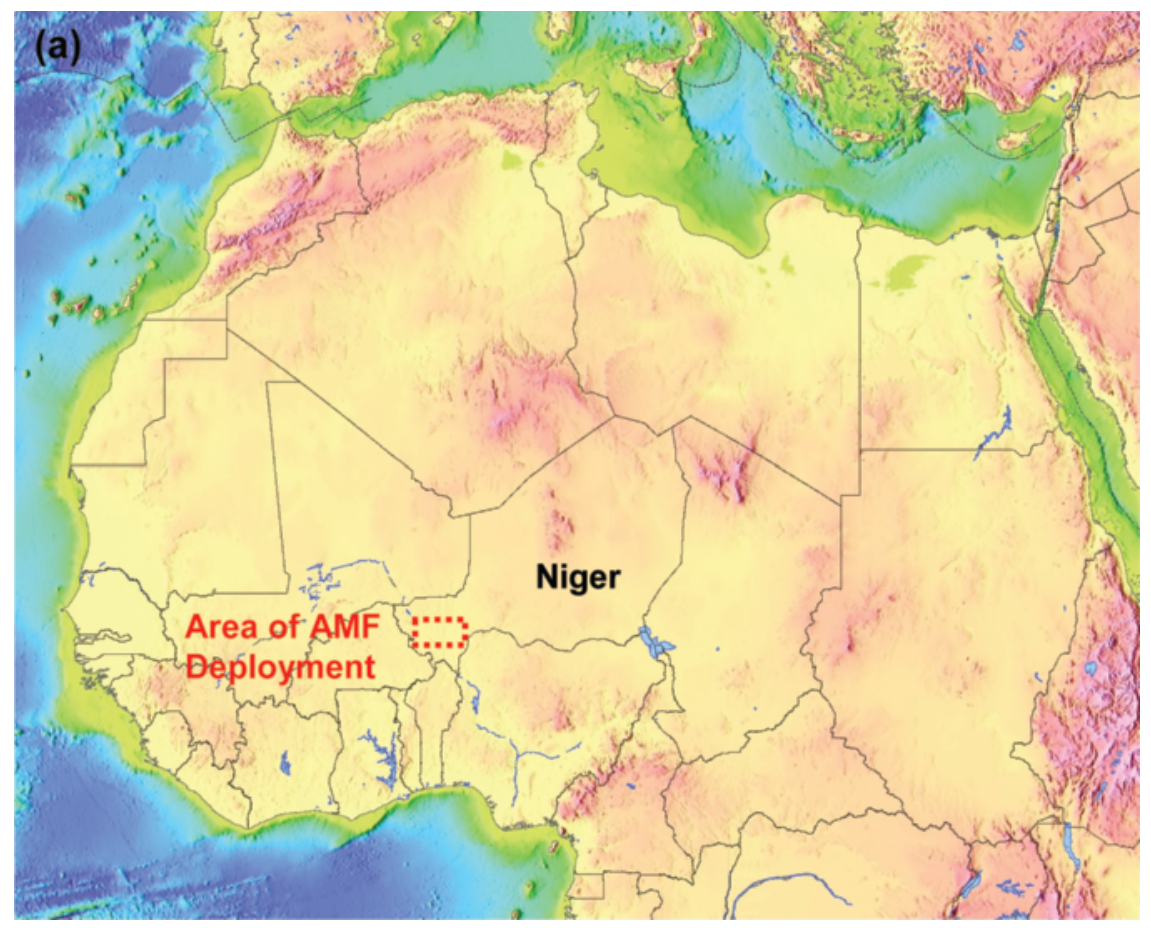

solar radiation vary from 67 to $98 \mathrm{~W} \mathrm{~m}^{-2}$ (Kiehl and Trenberth 1997; Wild 2005). The more recent estimates suggest that the atmosphere is more absorbing, and this leads to major problems when comparisons are made with models. It is relatively straightforward to tune a climate model to produce agreement with the observed globally averaged radiative fluxes at the top of the atmosphere, to within the errors in the satellite data. However, for most climate models there are substantial disagreements when the comparison is then made at the surface. Models typically produce

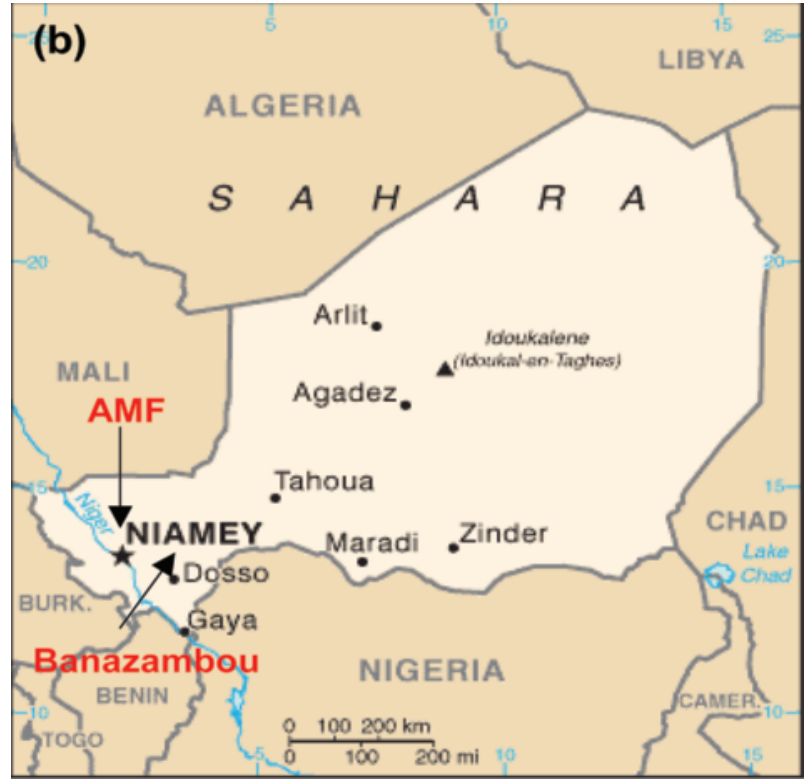

Fig. 3. Map of West Africa and enlargement of the area in Niger where the AMF was deployed.

reconciling long-term satellite measurements of the radiation budget at the top of the atmosphere with direct measurements of radiative fluxes at the surface and with models. Radiative fluxes at the top of the atmosphere are now well observed from satellites. In contrast, fluxes at the surface are less well observed, due to the variable quality and sparse distribution of measurements. As a result, estimates of the radiation balance of the atmosphere are not well constrained. For example, estimates of the global absorption of too much downward solar radiation and too little downward thermal radiation at the surface, compared with the measurements (Wild et al. 2006, 2001). This implies that the modeled atmosphere is too transparent and in particular that the atmosphere absorbs significantly more solar radiation than can be accounted for in most current models.

Several independent studies have arrived at this conclusion, which appears to be robust, despite the uneven distribution of surface observations, including a complete lack of data over much of the oceans (Gilgen and Ohmura 1999). Explanations of these results in terms of additional or excess solar absorption by clouds have been extremely contentious (Valero et al. 2004; Li et al. 2004) and no consensus has yet been reached on this problem. It is possible that absorbing aerosols may be making a contribution (Wild 2005), which emphasizes again the value of the measurements being made in Niamey.

Attempts to resolve the problems outlined above through field experiments have been beset by sampling problems. These problems include the limited global distribution of surface sites and limited instrumentation, the limited spatial and temporal sampling by in situ experiments using aircraft, and the limited spatial, temporal, and/or spectral sampling by satellites above the few well-instrumented surface sites. In order to minimize the sampling problems, an extended series of broadband observations from both space and the surface is required, with high temporal resolution. This in effect means a combination of 
a geostationary satellite and a well-instrumented surface site, which are the essential components of RADAGAST.

Components of RADAGAST. The choice of site for the AMF deployment was determined partly by the fact that Niamey is the center of operations for the Special Observing Periods of the AMMA project in 2006. AMMA seeks to improve understanding of the West African monsoon and its impact on both the local and global climate (Lebel et al. 2003). Niamey is an excellent site for the deployment, given the opportunities provided by the seasonal changes in meteorological conditions, the wide experience in working in this region, and the detailed logistical planning taking place for AMMA. The meteorological conditions experienced at Niamey include deep tropical convection in the wet season, and episodes of mineral dust (from the Sahara) and biomass burning aerosols in the dry season. The Sahara is the most important source of desert dust aerosols on Earth (Prospero and Lamb 2003), and the water vapor loading changes dramatically between the wet and dry seasons (Fig. 4). The divergences of atmospheric radiation through deep convection and aerosol are still poorly understood and this deployment will enable a concerted attack on these problems. The AMMA field phases extend over 2005-07 (including networks of surface flux measurements and some surface aerosol observations), with the main intensive observations in 2006 (January-September 2006). In particular, the Dust and Biomass Experiment (DABEX) employed both aircraft and surface sites in a successful study of dust and biomass aerosol in the region during January 2006. The AMF became operational at the beginning of 2006 and operated continuously throughout the year.

The Niamey site is also in a favorable position for coordinated observations with the Meteosat series of operational geostationary satellites. The current satellite, known as Meteosat-8, carries the GERB instrument, which is the first broadband radiometer to fly on a geostationary satellite (Harries et al. 2005; Allan et al. 2005). GERB observes the radiation budget with the unprecedented temporal resolution of $15 \mathrm{~min}$ : the same as the high-resolution Spinning Enhanced Visible and Infrared Imager (SEVIRI) on the same satellite (Schmetz et al. 2002). Further, GERB and SEVIRI instruments will fly on three satellites in this Meteosat series. The first of these, Meteosat-9, was launched in December 2005 and is expected to become the operational satellite in August 2007. For the RADAGAST project, data from the AMF, AMMA,
GERB, and SEVIRI provide a dataset that describes the surface and top-of-atmosphere radiative fluxes and the structure of the atmosphere between.

The data collected during RADAGAST will be especially valuable for evaluating climate and NWP models. In addition, there are many other projects that could benefit from the new data. These include the evaluation of surface fluxes derived from satellite data; studies of the radiative properties of water vapor, aerosols, and clouds; the diurnal cycle; and the structure of cloud and aerosol layers.

Details of the deployment in Africa. The Niamey Airport was chosen as the most appropriate location for the AMF to meet RADAGAST science objectives and for various logistical reasons (Fig. 5a). The photographs show the location of the main AMF equipment vans and the instrument stands. No structural modifications were made to the existing buildings. The AMF deployment, although primarily self-sufficient, was reliant on grid power (backed up by a standby generator). Data were transmitted from the airport site to central Niamey by a wireless link and subsequently to the main ARM archives, while data from the second site (see below) were logged locally and collected every week.

The instrument vans in the main site are individually air conditioned and were connected together

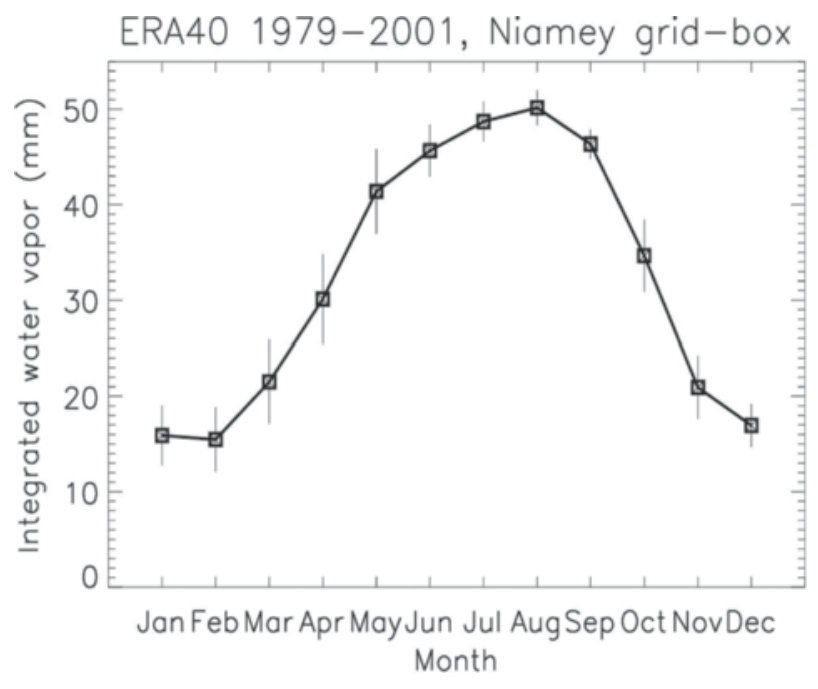

FIG. 4. Monthly mean integrated water vapor in the atmospheric column over Niamey, averaged from 1979 to 2001, from the 40-yr European Centre for MediumRange Weather Forecasts Re-Analysis (Uppala et al. 2005). The maximum value during this period was $54.9 \mathrm{~mm}$ (July 1979) and the minimum value was $9.7 \mathrm{~mm}$ (January 200I). Daily variations extend over an even larger range. 
by a tent that provides protection from blowing dirt, minimizes the loss of air conditioning when the van doors are opened, and provides additional security. Various instruments were mounted on stands located a hundred meters or so from the vans (Fig. 5b). While logistically convenient, the location of the site was quite close to the airport buildings and aircraft taxiways. This location compromised the turbulent flux measurements for specific wind directions and may have affected other surface measurements at certain times. A second, remote site was therefore established near Banizoumbou, Niger (Fig. 6), using solar power. This included a more limited range of instrumentation to measure basic meteorological fields and broadband fluxes. Turbulent fluxes were also being measured at Banizoumbou by researchers from the AMMA program. This site is representative of a large area of this part of the Sahel and so the observations will be of particular importance, as well as providing a comparison with the measurements from the airport site.
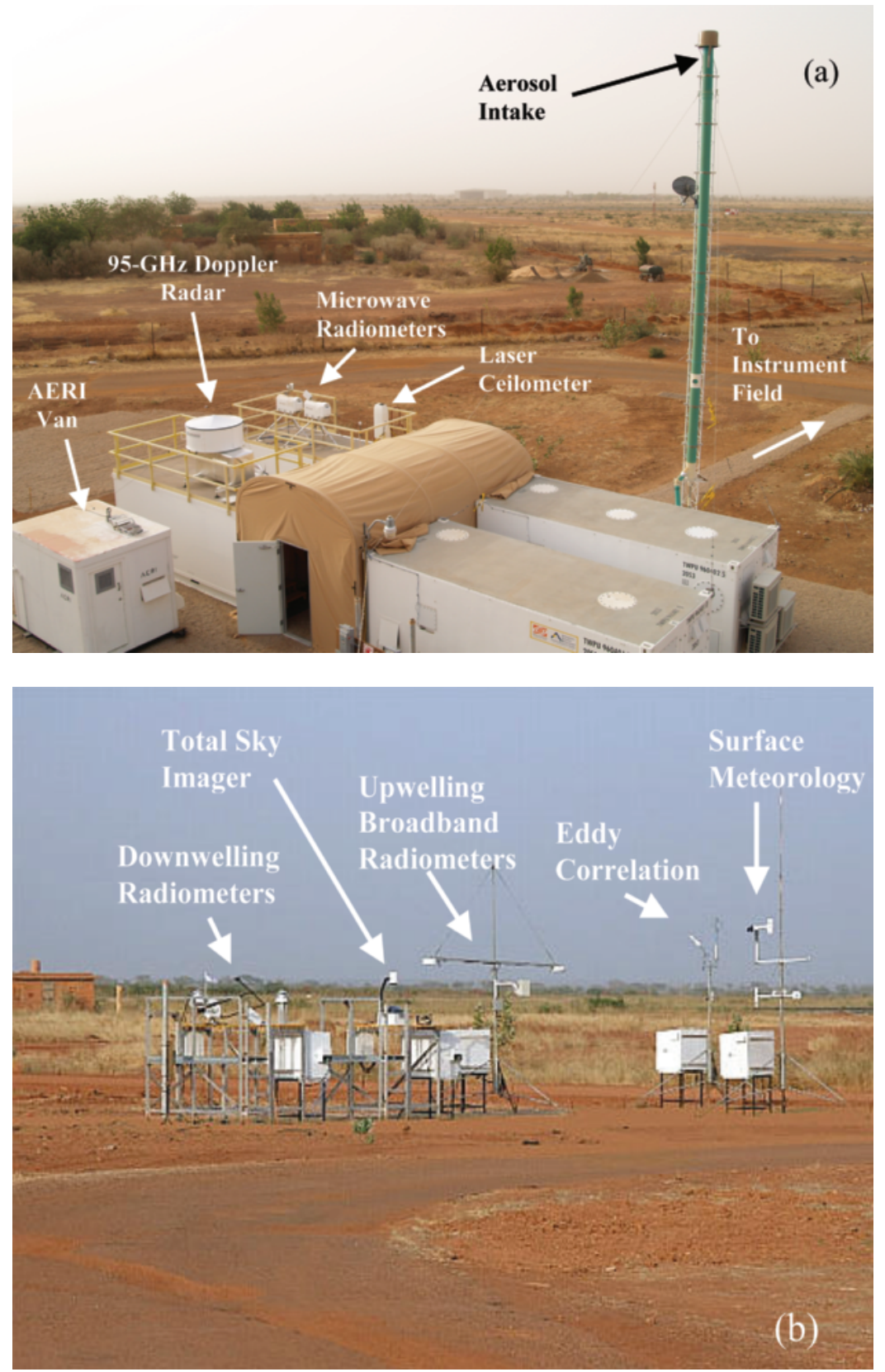

FIg. 5. (a) Overview of the AMF site in Niamey, and (b) the associated instrument field located approximately $100 \mathrm{~m}$ from the main facility.
Selected results. The goal of RADAGAST is to measure the fluxes at the surface using the AMF and at the top of the atmosphere using GERB and SEVIRI. These boundary conditions enable, in principle, a direct measurement of the radiation absorption properties of the atmosphere, although the difference in scale between the satellite pixels and the essentially point measurements at the surface needs to be addressed. The radiative absorption characteristics of cloud, Saharan dust, and biomassburning aerosol in the region are of particular interest. A tremendous dust outbreak occurred in early March over most of West Africa, and its effect on the radiation budget was determined from a combination of measurements by the AMF, GERB, and SERVI. This case study is discussed in detail by Slingo et al. (2006). In the remainder of this section, we briefly discuss two additional cases: one that demonstrates the capability of the AMF to characterize atmospheric and surface aerosol structure, and another that demonstrates the RADAGAST concept on a day with interesting, and somewhat typical, clouds.

Data collected on 9 July 2006 are rather typical of the monsoon season in the vicinity of Niamey. The 1135 UTC sounding, one of five soundings collected by the 
AMF on this day, reveals three decoupled layers: a shallow surface mixed layer (surface to $900 \mathrm{mb}$ ), a drier region in the middle midlevels (from 900 to $\sim 520 \mathrm{mb}$ ), and a relatively moist upper troposphere (Fig. 7). The shallow mixed layer near the surface represents the monsoon, as indicated by its southeasterly winds.

Cloud radar echoes depict cloudiness over the AMF site from 0000 to 1800 UTC (Fig. 8a), and Doppler velocities show liquid precipitation falling below $5 \mathrm{~km}$. While no radar bright band indicating a phase transition between ice and water is obvious (Fig. 8b), it is present in the crosspolarization channel (not shown). This precipitation originates as ice in deep ice clouds that lie in the moist upper troposphere that melts at the freezing level, which is approximately $600 \mathrm{mb}(4 \mathrm{~km})$. The microwave radiometer liquid water path, which is small through most of the day, indicates a lack of liquid water in the clouds except when it is precipitating. This observation, combined with the cloud radar reflectivity and cross-polar channel (not shown), confirms that the clouds in the upper troposphere were composed of ice. No measurable precipitation reached the surface on this day.

The vertical structure of aerosol in the subcloud layer is mapped using the backscatter from the lidar, corrected for attenuation (Fig. 8c). The orange layer below $5 \mathrm{~km}$ is indicative of strong scattering of the lidar beam by aerosol layers, and areas of red show the location of the optical cloud base, where multiple

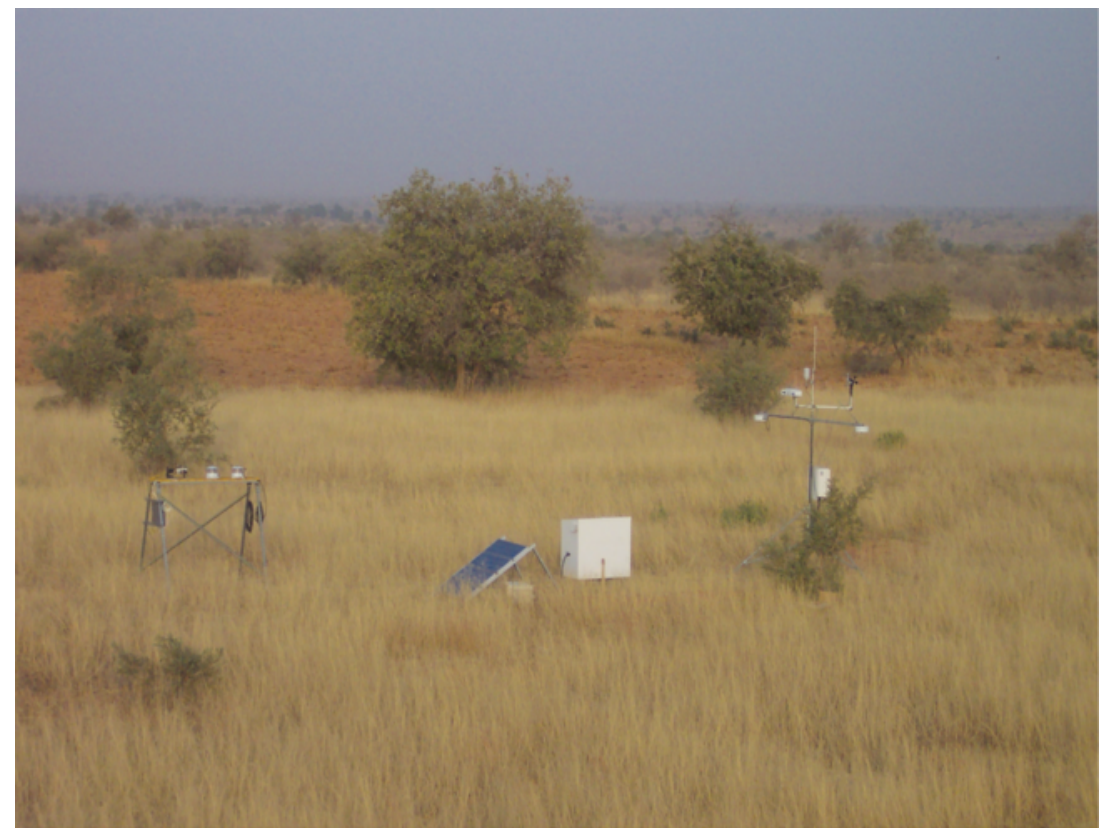

Fig. 6. The AMF ancillary site at Banazambou. Broadband downwelling radiation is measured on the platform on the left-hand side of the picture and broadband upwelling on the lateral beam attached to the pole on the right-hand side of the picture. Standard meteorological variables are measured atop the pole on the right-hand side of the picture and the solar panel that provides power is the tilted silver plate in the center.

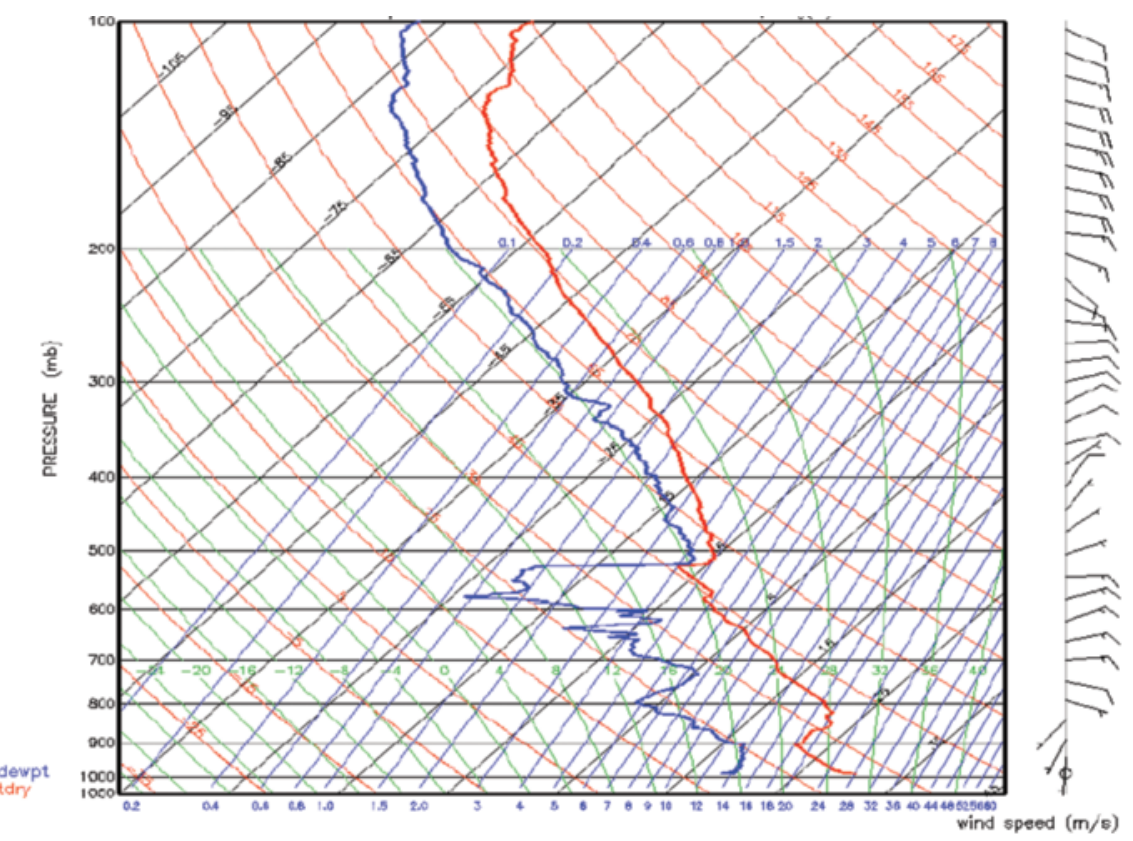

FIG. 7. A skew-T, log p diagram for the sounding launched on 9 Jul 2006 at II35 UTC from the AMF site in Niamey.

scattering quickly diffuses the beam. The apparent stratification of the backscatter signal, especially after 1200 UTC, is an indication of increased stability, and the thin layers of darker shades within the orange layer show evidence of multiple aerosol 


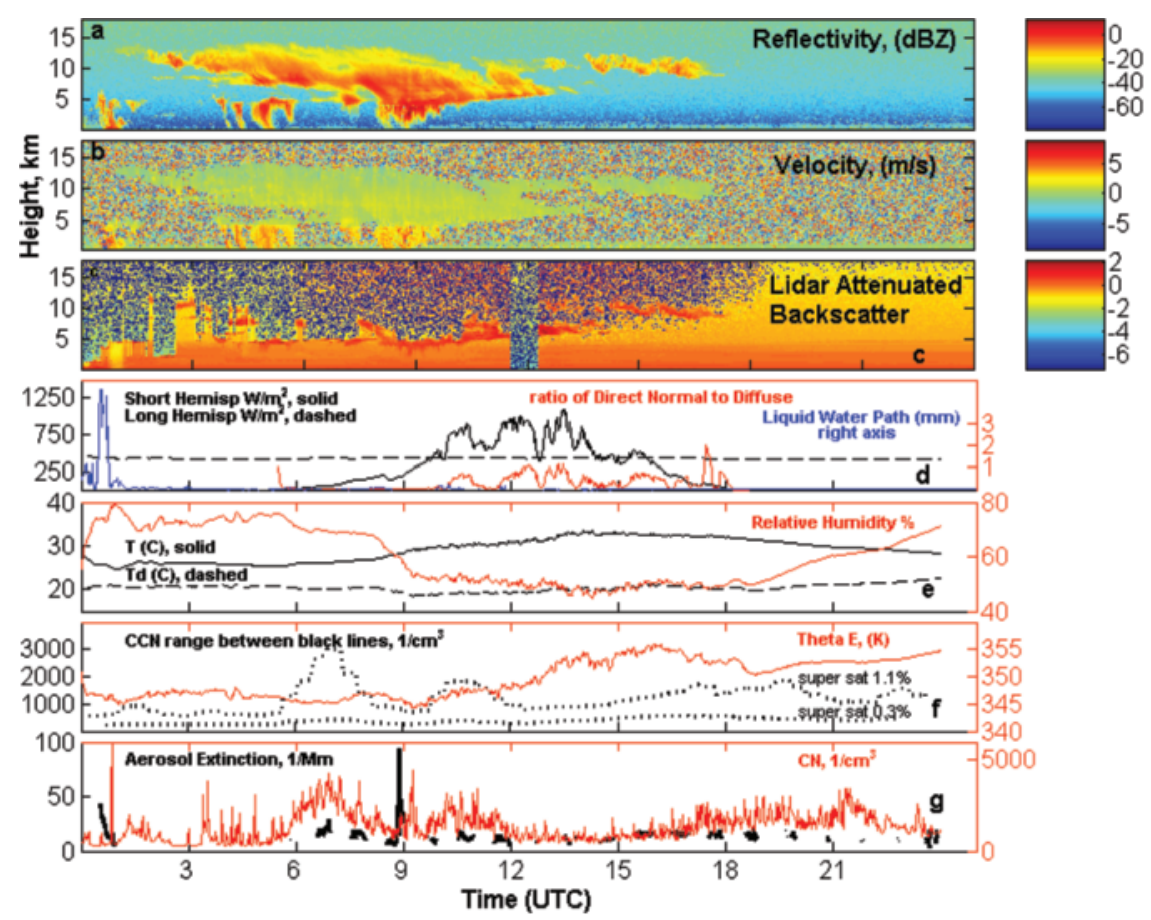

Fig. 8. Data from various AMF instruments collected on 9 Jul 2006 with red lines indicating the right scale, unless otherwise noted: (a) a time-height cross section of 95-GHz effective reflectivity factor (dBZ); (b) a time-height cross section of Doppler velocity in $\mathrm{m} \mathrm{s}^{-1}$ with warm colors indicating falling hydrometeors; (c) a time-height cross section of lidar attenuated backscatter with warm colors depicting larger values of backscatter; (d) a time series of liquid water path in $\mathrm{g} \mathrm{m}^{-2}$ (right axis is scale), the shortwave and longwave irradiances in $\mathrm{W} \mathrm{m}^{-2}$, and the ratio of direct-to-diffuse radiation; (e) a time series of the surface temperature, dewpoint temperature $\left({ }^{\circ} \mathrm{C}\right)$, and relative humidity (\%); (f) a time series of $\theta_{e}(K)$ and the number of $C C N$ at $0.3 \%$ and I.I\% supersaturation; and (g) the total number of $\mathrm{CN}\left(\mathrm{cm}^{-3}\right)$ and the aerosol optical extinction coefficient at $\sim 560 \mathrm{~nm}$.

layers. Aircraft penetrations of similar aerosol layers during DABEX show that the lowest $2 \mathrm{~km}$ contained a mixture of dust and biomass burning aerosol, while the layer from 2 to $5 \mathrm{~km}$ predominantly comprised biomass-burning aerosol (J. Haywood 2006, personal communication). It is not yet clear whether a similar differentiation takes place during the summer monsoon, when the occurrence of biomass burning is expected to be lower than during the dry season.

The shortwave radiation shows considerable structure through much of the daytime on 9 July 2006 due to cirrus cloudiness. The hemispheric flux varies by as much as $500 \mathrm{~W} \mathrm{~m}^{-2}$ through the day, and the diffuse irradiance varies widely depending on the details of cloud structure. The longwave flux varies between 400 and $450 \mathrm{~W} \mathrm{~m}^{-2}$ and, upon close inspection, shows evidence of clouds drifting over the site. The uniformity in the longwave flux is probably due to the high amounts of boundary layer water vapor and significant clouds, with aerosols as a tertiary effect (Fig. 8d).
Surface temperatures exceed $33^{\circ} \mathrm{C}\left(92^{\circ} \mathrm{F}\right)$ during the day (Fig. 8e) and the relative humidity is only $20 \%$. These variables can be used to compute the equivalent potential temperature $\theta_{e}$, which is conservative in all conditions including precipitation (Fig. 8f). It is, therefore, a tracer that can be used to identify changes in the air mass. A steady increase in $\theta_{e}$ after 0900 UTC corresponds to a change in wind direction, as indicated by the wind profiler (not shown) and the introduction of a new air mass over Niamey.

The nature of the aerosol at the surface is indicated by its activity spectrum, as discussed previously. The envelope of the activity spectrum, which is created by plotting the number of activated particles at the lowest and highest measured supersaturations, shows periods with sharply different aerosol characteristics that peak at $\sim 0700$ and $\sim 1100$ UTC. These periods are likely due to the introduction of biomass-burning aerosol at the surface in conjunction with morning cooking fires ( $~ 0700$ UTC), and with the mixing down of an elevated smoke layer in association with a downdraft created by evaporating precipitation ( 1100 UTC). Comparison of the envelope in the 0300-0600 UTC period, before the airmass change, with that of the 1500-2100 UTC, after the airmass change, suggests that the CCN activity spectrum has changed. Higher cloud droplet number concentrations are achievable in the new air mass, if sufficient updrafts are present to nucleate all particles.

The total condensation nuclei $(\mathrm{CN})$ counts (Fig. 8g) suggest that not all of the available $\mathrm{CN}$ are nucleated at supersaturations less than or equal to $1.1 \%$. At $\sim 0700$ UTC, for example, the total CN count is $\sim 400 \mathrm{~cm}^{-3}$, while the CCN count at $1.1 \%$ supersaturation is just over $3000 \mathrm{~cm}^{-3}$, so a higher supersaturation (updraft velocity) would be required to nucleate 
the remaining $\mathrm{CN}$. The aerosol extinction coefficient at $560 \mathrm{~nm}$ quantifies the amount of incident radiation that is scattered and absorbed by the $\mathrm{CN}$ at the surface. The aerosol extinction rises to a value of $\sim 25 \mathrm{Mm}^{-1}$ (per megameter), but aerosol extinction can be much greater at wavelengths $<500 \mathrm{~nm}$ in West Africa due to the preferential absorption of blue light by Saharan dust.

The 9 July 2006 case study presented above provides a snapshot of the capabilities of the AMF to characterize the atmospheric processes that are occurring at the deployment location. Combining shortwave and longwave radiation data from the AMF and GERB on 21 September 2006 produces a time series of atmospheric absorption (Fig. 9). One view of the top-of-atmosphere broadband fluxes comes from selecting the nearest GERB pixel to the AMF site in Niamey, thereby producing a $50-\mathrm{km}$ footprint that envelops the site. Another view is provided by the combined GERB and SEVIRI high-resolution product centered on the AMF site, which reduces the footprint to $10 \mathrm{~km}$ (GERB-HR). For discussion of the GERB products, see Harries et al. (2005) and Slingo et al. (2006). The contrast between the fluxes produced by these two footprints is a measure of the homogeneity of the cloud and aerosol structure in the vicinity of Niamey.

A daytime cirrus deck with a short-lived convective event that produced light precipitation at the surface ( 1100 UTC) demonstrates the RADAGAST concept (Fig. 9a). The AMF shows a significant reduction in incoming solar irradiance from sunrise through 1300 UTC associated with this cloud feature, followed by clearing in the late afternoon (Fig. 9b). In contrast, both GERB broadband shortwave products show increased flux at the top of the atmosphere during the passage of the cloud feature, relative to the late afternoon when skies clear. The cold cloud tops reduce outgoing longwave atmosphere. radiation, while the longwave radiation at the surface remains relatively constant, as discussed previously (Figs. 9b-c). Comparison of the GERB- Averaged Rectified Geolocated (ARG) and GERB-HR data, which show minimal difference in the shortwave and longwave fluxes while cloud are present $\left(\sim 50 \mathrm{~W} \mathrm{~m}^{-2}\right.$ for the shortwave component), suggests that the cloud feature is relatively uniform in the $50-\mathrm{km}$ region around the AMF site. The time series of net flux shows a positive shortwave flux divergence, which equates to heating in the atmospheric column by incoming solar energy (Fig. 9d). In contrast, negative values of longwave flux divergence are indicative of a net loss of energy in the infrared wavelengths from the atmosphere to space and to the surface. The net flux divergence demonstrates net absorption (warming) of the column during the middle of the day, and net cooling in the morning and evening.

The diurnal tendencies of total atmospheric longwave, shortwave, and net absorption are extremely useful and can be used to constrain calculations of the atmospheric heating rate profile, which provide a more detailed characterization of the interaction be-

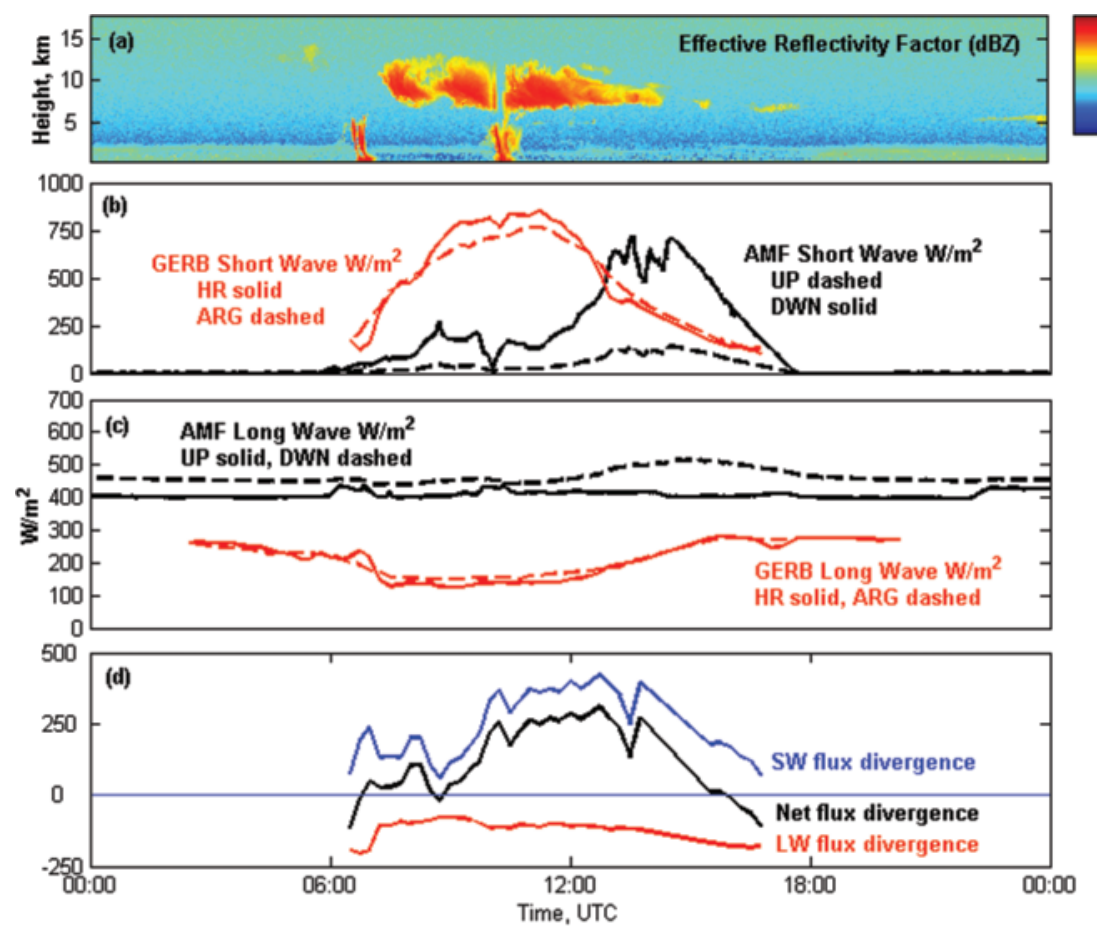

FIG. 9. Data from the AMF and GERB/SEVIRI satellite data for 2I Sep 2006. (a) A time-height cross section of $95-\mathrm{GHz}$ effective reflectivity factor (dBZ), (b)-(c) the broadband shortwave and longwave fluxes for the 10 - (HR) and 50-km (ARG) GERB footprints centered on the Niamey AMF site and the upwelling (dashed) and downwelling (solid) measurements from the AMF, and (d) the longwave, shortwave, and net divergence of the fluxes across the atmosphere. Note that negative values indicate a loss of energy from the 
tween clouds, aerosols, and radiation. Calculations of the atmospheric heating rate profile for RADAGAST require specification of the profiles of clouds and aerosols, along with standard thermodynamic data, so the AMF data presented above represent the path forward toward the longer-term goal of a better understanding of the profile of atmospheric heating in West Africa.

SUMMARY. The AMF is a powerful new resource for use by the international climate and atmospheric science community. Its design echoes that of the fixed ARM sites and benefits from over a decade of experience in collecting datasets that can be used to improve GCMs. It is deployed for periods of 6-12 months on the basis of a competitive proposal process, and its initial deployments have drawn considerable interest in the international atmospheric science community. It is expected that the AMF will provide seminal data that can be used to improve the accuracy of GCMs in regions that are currently undersampled.

The combination of continuous, detailed information about the state of the atmospheric column from the AMF and continuous broadband radiation measurements from satellites in the vicinity of Niamey, Niger, presented above represent a new paradigm for atmospheric science in that the surface and top-of-the-atmosphere broadband radiative fluxes and computed heating rate profiles are available continuously over a diurnal cycle. Such observations have not been possible up to now, because all of the other satellites with broadband radiation sensors are in polar orbits, rather than geostationary.

The success of the first AMF as inspired planning for a second facility, to be built and deployed within the next three to four years. This new facility will have capabilities that complement the current facility and may include scanning sensors.

ACKNOWLEDGMENTS. Many dedicated professionals have contributed to the design, construction, and deployment of the ARM Mobile Facility. Mike Alsop, Betsy Andrews, Mary Jane Bartholomew, Dick Egan, Larry Jones, Pavlos Kollias, Kim Nitschke, John Ogren, Rex Peterson, Doug Sisterton, Jimmy Voyles, and Kevin Widener have made notable contributions. We are also indebted to our program manager at the Department of Energy, Dr. Wanda Ferrell, and to Dr. Tom Ackerman, past ARM Chief Scientist, for their efforts to develop the AMF. We are especially grateful to Mary Jane Bartholomew for constructing Figs. 8 and 9, to Conner Flynn for applying the lidar overlap correction in Fig. 8c, to Richard Allan for providing Fig. 4, to Nazim Ali Bharmal for providing the
GERB data shown in Fig. 9, and to John Ogren and Anne Jefferson for Fig. $2 \mathrm{~b}$ and many useful comments. This manuscript has been authored by Brookhaven Science Associates, LLC, under Contract DE-AC02-98CH10886 with the U.S. Department of Energy. The U.S. Government retains, and the publisher, by accepting the article for publication, acknowledges, a worldwide license to publish or reproduce the published form of this manuscript, or allow others to do so, for the U.S. Government purposes.

\section{REFERENCES}

Ackerman, T. A., and G. M. Stokes, 2003: The Atmospheric Radiation Measurement Program. Phys. Today, 56, 38-45.

Allan, R. P., A. Slingo, S. F. Milton, and I. Culverwell, 2005: Exploitation of Geostationary Earth Radiation Budget data using simulations from a numerical weather prediction model: Methodology and data validation. J. Geophys. Res., 110, D14111, doi:10.1029/ 2004JD005698.

Anderson, T. L., and J. A. Ogren, 1998: Determining aerosol radiative properties using the TSI 3563 integrating nephalometer. Aerosol Sci. Technol., 29, 57-69.

—, D. S. Covert, J. D. Wheeler, J. M. Harris, K. D. Perry, B. E. Trost, D. J. Jaffe, and J. A. Ogren, 1999: Aerosol backscatter fraction and single scattering albedo: Measured values and uncertainties at a coastal location in the Pacific Northwest. J. Geophys. Res., 104, 26 793-26 807.

Andrews, E., and Coauthors, 2006: Comparison of methods for deriving aerosol asymmetry parameter. J. Geophys. Res., 111, D05504, doi:10.1029/ 2004JD005734.

Bond, T. C., T. L. Anderson, and D. Campbell, 2001: Calibration and intercomparison of filter-based measurements of visible light absorption by aerosols. Aerosol Sci. Technol., 30, 582-600.

Cahalan, R. F., and Coauthors, 2005: The I3RC: Bringing together the most advanced radiative transfer tools for cloudy atmospheres. Bull. Amer. Meteor. Soc., 86, 1275-1293.

Campbell, J. R., D. L. Hlavka, E. J. Welton, C. J. Flynn, D. D. Turner, J. D. Spinhirne, and V. S. Scott, 2002: Full-time eye safe cloud and aerosol lidar observation at the atmospheric radiation measurement program sites: Instruments and data processing. J. Atmos. Oceanic Technol., 19, 431-442.

Clothiaux, E. E., M. A. Miller, B. A. Albrecht, T. A. Ackerman, J. Verlinde, D. M. Babb, R. M. Peters, and W. J. Syrett, 1995: An evaluation of a 94-GHz radar for remote sensing of cloud properties. J. Atmos. Oceanic Technol., 12, 201-229. 
Collard, A. D., S. A. Ackerman, W. L. Smith, X. Ma, H. E. Revercomb, R. O. Knuteson, and S. C. Lee, 1995: Cirrus cloud properties derived from high spectral resolution infrared spectrometry during FIRE II. Part III: Ground-based HIS results. J. Atmos. Sci., 52, 4264-4275.

Ecklund, W. L., D. A. Carter, and B. B. Balsley, 1988: A UHF wind profiler for the boundary layer: Brief description and initial results. J. Atmos. Oceanic Technol., 5, 432-441.

Feltz, W. F., W. L. Smith, R. O. Knuteson, H. E. Revercomb, H. M. Woolf, and H. B. Howell, 1998: Meteorological applications of temperature and water vapor retrievals form ground-based Atmospheric Emitted Radiance Interferometer (AERI). J. Appl. Meteor., 37, 857-875.

Fiebig, M., and J. A. Ogren, 2006: Retrieval and climatology of the aerosol asymmetry parameter in the NOAA aerosol monitoring network. J. Geophys. Res., 111, D21204, doi:10.1029/2005JD006545.

Gary, B. L., 1988: Passive microwave temperature profiler. Rep. JPL-D-5484, Jet Propulsion Laboratory, California Institute of Technology, $25 \mathrm{pp}$.

Gilgen, H., and A. Ohmura, 1999: The Global Energy Balance Archive. Bull. Amer. Meteor. Soc., 80, 831-850.

Gossard, E. E., 1988: Measuring drop-size distributions in clouds with a clear-air-sensing Doppler radar. J. Atmos. Oceanic. Technol., 5, 640-649.

—, R. B. Chadwick, W. D. Neff, and K. P. Moran, 1982: The use of ground-based Doppler radars to measure gradients, fluxes and structure parameters in elevated layers. J. Appl. Meteor., 21, 211-226.

Güldner, J., and D. Spanküch, 2001: Remote sensing of the thermodynamic state of the atmospheric boundary layer by ground-based microwave radiometry. J. Atmos. Oceanic Technol., 18, 925-933.

Harries, J. E., and Coauthors, 2005: The Geostationary Earth Radiation Budget (GERB) experiment. Bull. Amer. Meteor. Soc., 86, 945-960.

Harrison, L., and J. Michalsky, 1994a: Automated multifilter rotating shadow-band radiometer: An instrument for optical depth and radiation measurements. Appl. Opt., 33, 5118-5125.

$\longrightarrow$, and — 1994b: Objective algorithm for the retrieval of optical depths from ground-based measurements. Appl. Opt., 33, 5126-5132.

Haywood, J., and O. Boucher, 2000: Estimates of the direct and indirect radiative forcing due to tropospheric aerosols: A review. Rev. Geophys., 38, 513-543.

Huschke, R. E., Ed., 1959: Glossary of Meteorology. Amer. Meteor. Soc., 638 pp.
Kiehl, J. T., and K. E. Trenberth, 1997: Earth's annual global mean energy budget. Bull. Amer. Meteor. Soc., 78, 197-208.

Kollias, P., and B. A. Albrecht, 2000: The turbulence structure in a continental stratocumulus cloud from millimeter-wavelength radar observations. J. Atmos. Sci., 57, 2417-2433.

,-- , R. Lhermitte, and A. Savtchenko, 2001: Radar observations of updrafts, downdrafts, and turbulence in fair weather cumuli. J. Atmos. Sci., 58, 1750-1766.

—, E. E. Clothiaux, B. A. Albrecht, M. A. Miller, K. P. Moran, and K. L. Johnson, 2005: The atmospheric radiation measurement program cloud profiling radars: An evaluation of signal processing and sampling strategies. J. Atmos. Oceanic Technol., 22, 930-947.

— , E. Luke, M. Miller, and B. Albrecht, 2006: Radar Doppler spectra recording at the ARM sites. An insight to cloud microphysics and turbulence. Proc. Fourth European Conf. on Radar in Meteorology and Hydrology, Barcelona, Spain, ERAD, 233-235.

— E. E. Clothiaux, M. A. Miller, B. A. Albrecht, G. L. Stephens, and T. P. Ackerman, 2007: Millimeterwavelength radars-New frontier in atmospheric cloud research. Bull. Amer. Meteor. Soc., in press.

Lebel, T., J.-L. Redelsperger, and C. Thorncroft, 2003: African Monsoon Multidisciplinary Analysis (AMMA) Project. GEWEX News, Vol. 13, No. 4, International GEWEX Project Office, 8-9.

Leclerc, M. Y., S. Chen, and B. Lamb, 1997: Observations of large eddy simulation modeling of footprints in the lower convective boundary layer. J. Geophys. Res., 102 (D8), 9323-9334.

Lhermitte, R. M., 1987: A 94-GHz Doppler radar for cloud observations. J. Atmos. Oceanic Technol. ,4, 36-48.

Li, Z., Wiscombe, W., G. L. Stephens, and T. P. Ackerman, 2004: Response. Science, 305, 1240.

Liljegren, J. C., E. E. Clothiaux, G. Mace, S. Kato, and X. Dong, 2001: A new retrieval for cloud liquid water path using a ground-based microwave radiometer and measurements of cloud temperature. J. Geophys. Res., 106, 14 485-14 500.

Long, C. N., and J. J. DeLuisi, 1998: Development of an automated hemispheric sky imager for cloud fraction retrievals. Proc. 10th Symp. on Meteorological Observations and Instrumentation, Phoenix, AZ, Amer. Meteor. Soc., 171-174.

Lubin, D., and A. M. Vogelmann, 2006: A climatologically significant aersol longwave indirect effect in the arctic. Nature, 439, 453-456. 
Moore, C. J., 1986: Frequency response corrections for eddy correlation systems. Bound.-Layer Meteor., 37, 17-35.

Pilewskie, P., M. Rabbette, R. Bergstrom, J. Marquez, B. Schmid, and P. B. Russell, 2000: The discrepancy between measured and modeled downwelling solar irradiance at the ground: dependence on water vapor. Geophys. Res. Lett., 27, 137-140.

Prospero, J. M., and P. J. Lamb, 2003: African droughts and dust transport to the Caribbean: Climate change implications. Science, 302, 1024-1027.

Ptashnik, I. V., K. M. Smith, K. P. Shine, and D. A. Newnham, 2004: Laboratory measurements of water vapour continuum absorption in spectral region 5000-5600 $\mathrm{cm}^{-1}$ : Evidence for water dimers. Quart. J. Roy. Meteor. Soc., 130, 2391-2408.

Roberts, G. C., and A. Nenes, 2005: A continuous-flow streamwise thermal-gradient $\mathrm{CCN}$ chamber for atmospheric measurements. Aerosol Sci. Technol., 39, 206-221.

Schmetz, J., P. Pili, S. Tjemkes, D. Just, J. Kerkman, S. Rota, and A. Ratier, 2002: An introduction to Meteosat Second Generation (MSG). Bull. Amer. Meteor. Soc., 83, 977-992.

Schuepp, P. H., J. I. MacPherson, and R. L. Desjardins, 1992: Adjustment of footprint correction for airborne flux mapping over the FIFE site. J. Geophys. Res., 97 (D17), 18 455-18 466.

Slingo, A., and Coauthors, 2006: Observations of the impact of a major Saharan dust storm on the atmospheric radiation balance. Geophys. Res. Lett., 33, L24817, doi:10.1029/2006GL027869.

Smith, W. L., W. F. Feltz, R. O. Knuteson, H. E. Revercomb, H. B. Howell, and H. M. Woolf, 1999: The retrieval of planetary boundary structure using ground-based infrared spectral radiance measurements. J. Atmos. Oceanic Technol., 16, 323-333.

Spinhirne, J. D., 1993: Micro pulse lidar. IEEE Trans. Geosci. Remote Sens., 31, 48-55.

Stokes, G. M., and S. E. Schwartz, 1994: The Atmospheric Radiation Measurement (ARM) Program:
Programmatic background and design of the cloud and radiation testbed. Bull. Amer. Meteor. Soc., 75, 1201-1221.

Turner, D. D., 2005: Arctic mixed-phase cloud properties from AERI lidar observations: Algorithm and results from SHEBA. J. Appl. Meteor., 44, 427-444.

— , and Coauthors, 2004: The QME AERI LBLRTM: A closure experiment for downwelling high spectral resolution infrared radiance. J. Atmos. Sci., 61, 2657-2675.

— Their importance and our challenge. Bull. Amer. Meteor. Soc., 88, 177-190.

Uppala, S. M., and Coauthors, 2005: The ERA-40 re-analysis. Quart. J. Roy. Meteor. Soc., 131, 29613012.

Valero, F. P. J., R. D. Cess, and S. K. Pope, 2004: Disagreements over cloud absorption. Science, 305, 1239.

Webb, E. K., G. I. Pearman, and R. Leuning, 1980: Correction of flux measurements for density effects due to heat and water vapour transfer. Quart. J. Roy. Meteor. Soc., 106, 85-100.

Westwater, E., Y. Han, M. Shupe, and S. Matrosov, 2001: Analysis of integrated cloud liquid and precipitable water vapor retrievals from microwave radiometers during the Surface Heat Budget of the Arctic Ocean project. J. Geophys. Res., 106, 32 019-32 030.

Wild, M., 2005: Solar radiation budgets in atmospheric model intercomparisons from a surface perspective. Geophys. Res. Lett., 32, L07704, doi:10.1029/ 2005 GL022421.

—, A. Ohmura, H. Gilgen, J.-J. Morcrette, and A. Slingo, 2001: Evaluation of downward longwave radiation in general circulation models. J. Climate, 14, 3227-3239.

— C. N. Long, and A. Ohmura, 2006: Evaluation of clear-sky solar fluxes in GCMs participating in AMIP and IPCC-AR4 from a surface perspective. J. Geophys. Res., 111, D01104, doi:10.1029/2005JD006118. 